\title{
GROWTH ANALYSIS OF CADMIUM SULFIDE THIN FILMS BY ATOMIC FORCE MICROSCOPY
}

\author{
H.R. Moutinho, R.G. Dhere, K. Ramanathan, P. Sheldon and L.L. Kazmerski \\ National Renewable Energy Laboratory, 1617 Cole Blvd., Golden CO 80401
}

\begin{abstract}
CdS films have been deposited by solution growth on $\mathrm{SnO}_{2}$ and glass substrates. Nucleation on $\mathrm{SnO}_{2}$ occurs at early deposition times, and complete conformal coverage is observed at low thickness values. The average grain size of the CdS films is established at these early times. In films deposited on glass substrates, nucleation is slower and occurs through 3-dimensional islands that increase in size and number as deposition proceeds. Optical measurements show that the bandgap values of $\mathrm{CdS}$ films deposited on $\mathrm{SnO}_{2}$ depend mainly on substrate structure. Hydrogen heat treatment does not affect the surface morphology of the samples, but decreases bandgap values.
\end{abstract}

\section{INTRODUCTION}

Very thin CdS films are commonly used as window layers in thin-film solar cells. Because light absorbed in CaS does not significantly contribute to the collected photocurrent, it is desired that this layer have the minimum thickness possible. The minimum thickness should allow for a CdS conformal coverage of the substrate without formation of defects that could shunt the cell. Solution-grown CdS thin films offer the advantages of conformal coverage on rough surfaces at minimal thicknesses, ease of deposition, and low cost [1,2].

In this study, we investigate the growth of $\mathrm{CdS}$ deposited on $\mathrm{SnO}_{2}$ and glass under different conditions. The primary analytical technique used was atomic force microscopy (AFM), which provides the following desired characterization: extremely high magnifications, highresistivity sample analysis, and determination of roughness values. We have also performed transmittance and reflectance measurements to obtain optical bandgap values of the deposited films.

\section{EXPERIMENTAL}

CdS films were deposited by the chemical solution growth technique. Two different processes were used, based mainly on the quantities of ammonium hydroxide and ammonium acetate used. In both processes an initial solution of de-ionized water, ammonium acetate, and cadmium acetate (the source of
Cd) was prepared. In process A, thiourea (the source of S) was then added, and, at last, the reaction was initiated with a solution of ammonium hydroxide in de-ionized water. Two deposition temperatures were used, $70^{\circ} \mathrm{C}$ and $85^{\circ} \mathrm{C}$. The solution was slightly basic, with $\mathrm{pH}$ just above 7 . In process $B$, the concentration of ammonium hydroxide and ammonium acetate were increased many times. In this process, thiourea was the last chemical added, and the one to start the growth reaction. The films were deposited at $90^{\circ} \mathrm{C}$. The solution was highly basic, with $\mathrm{pH}$ close to 10 . Process $\mathrm{A}$ is similar to the one used by Devaney [3], and process $B$ is similar to the one used by Chu [4].

In the solution growth method, CdS can grow on the substrate (heterogeneous process) or in the solution itself (homogeneous process). The heterogeneous process in general gives rise to films with quality suitable for photovoltaic application. The homogeneous process, which can be minimized by reducing the rate of formation of CdS, gives rise to CdS precipitates that deposit loosely on the substrate. These precipitates may come out of the film after deposition, giving rise to pinholes, as been observed by Danaher [5]. At early deposition stages, the solution is clear, but as homogeneous reaction takes place, it begins to get an orange coloration. Experimentally, one can determine when the reaction should be stopped, to prevent significant incorporation of CdS (coming from homogeneous reaction) in the film. This criterion was used to determine when to stop the deposition.

Besides borosilicate and sodalime glass, two structures were used as substrates:

- LOF $\mathrm{SnO}_{2}$ /sodalime glass

- Intrinsic $\mathrm{SnO}_{2}$ /Solarex $\mathrm{SnO}_{2}$ /borosilicate glass.

For each deposition, the substrates were removed from the solution at different times so that films with different thicknesses could be obtained. Film thickness varied from $10 \mathrm{~nm}$ to $150 \mathrm{~nm}$.

Some CdS films were heat-treated in hydrogen to promote recrystallization and to remove oxygen from the films, which increases carrier concentration and mobility $[6,7]$.

AFM analysis [8] was performed using a Park Scientific Autoprobe LS instrument in contact mode, using Si cantilevers. Transmittance and reflectance analyses were done in a Cary 2300 spectrophotometer equipped with integrating sphere. 


\section{RESULTS AND DISCUSSION}

AFM images of CdS films deposited on $\mathrm{SnO}_{2}$ revealed the surface morphology of both films. The CdS formed a secondary structure over the $\mathrm{SnO}_{2}$ film. At early stages of growth, CdS films already show complete conformal coverage. This is an important result, because the thinner the CdS layer, the smaller the optical loss will be in the cell. The surface morphology of a sample after 15 minutes into growth is shown in Fig. 1. The $\mathrm{SnO}_{2}$ structure, with large grains, is clearly distinguishable underneath the small-grain CdS thin film. The thickness of the CdS layer was about $30 \mathrm{~nm}$. All films deposited on $\mathrm{SnO}_{2}$, independent of growth process, showed complete coverage at thicknesses of $40 \mathrm{~nm}$ or less. We also found that grain growth occurs much faster horizontally than vertically in the initial stages. This is clearly seen in Table 1 , when one compares grain size and thickness for the thinnest films. Another observation is that the average grain size of the films are defined at early deposition times. Later grain growth, when it occurs, is not significant, as also shown in Table 1.

We have not found many differences in surface morphology in samples grown by different processes and/or deposited on different $\mathrm{SnO}_{2}$ films. The average grain size for most films was around $60 \mathrm{~nm}$, with the exception of films grown at $70^{\circ} \mathrm{C}$, which had an average grain size close to $35 \mathrm{~nm}$. For the latter, it seems that the lower temperature favored a higher density of nucleation sites, and as a result, the smaller grain size.

After the initial nucleation process, the grains seem to grow independently of each other in a 3dimensional process, while new grains are generated on the existing structure. This explains why the average grain size does not change after early deposition times, because new grains will prevent the growth of adjacent ones. It also explains the large variation in grain size observed, because old larger grains, as well as new smaller grains, are present. In a sample with an average grain size of $60 \mathrm{~nm}$, grains as small as $30 \mathrm{~nm}$ and as large as $90 \mathrm{~nm}$ are observed. This is shown in Fig. 2.

Another important parameter shown in Table 1 is the rms roughness. The roughness values for all films agree well with the ones for the respective $\mathrm{SnO}_{2}$ substrate. This is a very important result because it indicates that the growth is conformal and that the CdS thickness is uniform. If the growth were not conformal, for instance, with films growing preferentially at grain boundaries, the roughness values for the films would probably be smaller than the ones for the substrates.

It is important to note that the values obtained for grain size and roughness are averages and that there is a statistical variation associated with them, which depends on the location on the sample where the measurement was performed. To minimize these errors, we have done many measurements of each parameter. However, we still estimate an uncertainty around $10 \%$ and $15 \%$ in the reported values for roughness and grain size, respectively, due mainly to statistical fluctuations in the

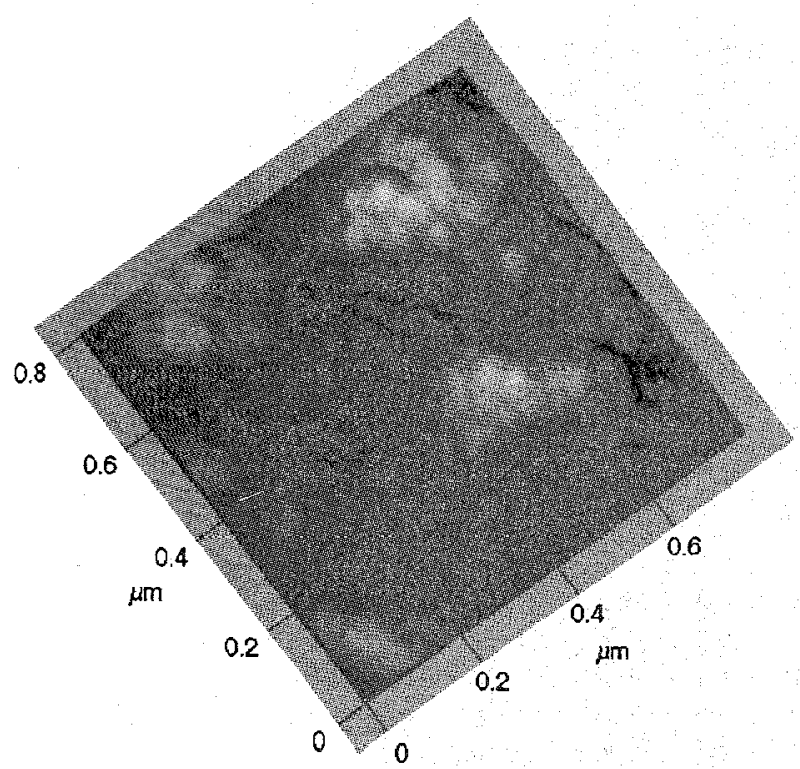

Fig. 1. CdS thin film (approximately $30 \mathrm{~nm}$ thick) deposited on $\mathrm{SnO}_{2}$.

Table 1. Average grain size (GS), rms roughness (R), and film thickness (d) for CdS films deposited with different parameters on $\mathrm{SnO}_{2}$. LOF means LOF $\mathrm{SnO}_{2}$ deposited on sodalime glass. Sol means Solarex $\mathrm{SnO}_{2}$ deposited on borosilicate glass, with an intrinsic $\mathrm{SnO}_{2}$ layer on top. Last two lines show values of $G S, R$, and $d$ for both $\mathrm{SnO}_{2}$ used in the depositions.

\begin{tabular}{|c|c|c|c|c|c|}
\hline $\begin{array}{l}\text { Growth } \\
\text { Process }\end{array}$ & Substrate & $\begin{array}{c}\mathrm{T} \\
\left({ }^{\circ} \mathrm{C}\right)\end{array}$ & $\begin{array}{c}\text { GS } \\
(\mathrm{nm})\end{array}$ & $\begin{array}{c}R \\
(\mathrm{~nm})\end{array}$ & $\begin{array}{c}d \\
(n m)\end{array}$ \\
\hline \multirow[t]{3}{*}{ A } & \multirow[t]{3}{*}{ LOF } & \multirow[t]{3}{*}{70} & 31 & 34 & 10 \\
\hline & & & 36 & 35 & 17 \\
\hline & & & 34 & 33 & 50 \\
\hline \multirow[t]{3}{*}{ A } & \multirow[t]{3}{*}{ LOF } & \multirow[t]{3}{*}{85} & 56 & 33 & 10 \\
\hline & & & 57 & 34 & 36 \\
\hline & & & 61 & 36 & 100 \\
\hline \multirow[t]{3}{*}{ A } & \multirow[t]{3}{*}{ Sol } & \multirow[t]{3}{*}{85} & 56 & 23 & 10 \\
\hline & & & 61 & 23 & 36 \\
\hline & & & 62 & 23 & 120 \\
\hline \multirow[t]{3}{*}{ B } & \multirow[t]{3}{*}{ LOF } & \multirow[t]{3}{*}{90} & 52 & 33 & 21 \\
\hline & & & 60 & 34 & 75 \\
\hline & & & 59 & 32 & 138 \\
\hline \multirow[t]{3}{*}{ B } & \multirow[t]{3}{*}{ Sol } & \multirow[t]{3}{*}{90} & 59 & 22 & 45 \\
\hline & & & 55 & 24 & 89 \\
\hline & & & 62 & 22 & 140 \\
\hline \multicolumn{3}{|c|}{ LOF $\mathrm{SnO}_{2}$} & 210 & 34 & - \\
\hline & טוני & & 95 & 23 & $=$ \\
\hline
\end{tabular}

value for these parameters from point to point in the sample.

CdS films were also deposited on sodalime and borosilicate glass substrates. Because these substrates 


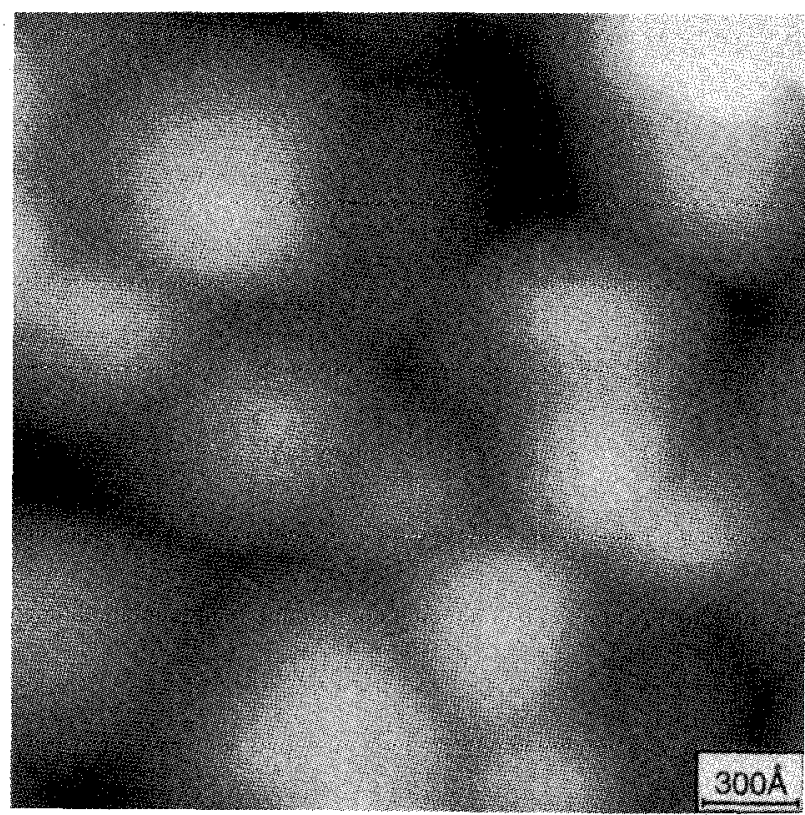

Fig. 2. AFM image of a CdS thin film grown on $\mathrm{SnO}_{2}$ showing a large variation of grain sizes.

are much smoother than $\mathrm{SnO}_{2}$, it is easier to observe the nucleation process. The nucleation and growth is very different than in films deposited on $\mathrm{SnO}_{2}$. For glass substrates, complete coverage does not occur at early times, and nucleation and growth takes place through 3dimensional islands.

Films deposited on sodalime substrates using process B showed scattered 3-dimensional islands with diameters varying from $27 \mathrm{~nm}$ to $92 \mathrm{~nm}$, and height from 3 $\mathrm{nm}$ to $17 \mathrm{~nm}$, at 10 minutes into growth. The subsequent films showed a continuous grain structure with the film grown for 40 minutes showing average grain size of 80 $\mathrm{nm}$.

For the borosilicate substrate (also deposited using process $\mathrm{B}$ ), nucleation was first observed at 15 minutes into growth, with very few islands with diameters varying from $60 \mathrm{~nm}$ to $90 \mathrm{~nm}$ and height from $5 \mathrm{~nm}$ to 15 $\mathrm{nm}$. As deposition time increased, the number of islands also increased, as well as their maximum size. At 25 minutes, a non-continuous structure was observed, as shown in Fig. 3. The CdS grain size varied from $80 \mathrm{~nm}$ to $110 \mathrm{~nm}$ and the height from $50 \mathrm{~nm}$ to $60 \mathrm{~nm}$. At 40 minutes, the CdS structure was almost continuous, but some very small open areas, with depth varying from 50 $\mathrm{nm}$ to $60 \mathrm{~nm}$, were still visible. The average grain size was $88 \mathrm{~nm}$.

The roughness measured for the borosilicate substrate was $0.8 \mathrm{~nm}$ and for the continuous CdS film was $7 \mathrm{~nm}$. This low value for the CdS roughness indicates that the roughness of $\mathrm{CdS}$ deposited on $\mathrm{SnO}_{2}$ is mainly due to the substrate structure, which reinforces our argument that the CdS coverage on $\mathrm{SnO}_{2}$ is comformal and uniform.
The differences in nucleation and growth mechanisms observed in samples deposited on $\mathrm{SnO}_{2}$ and glass are attributed to the fact that the rough $\mathrm{SnO}_{2}$ provides many more nucleation sites than the very smooth glass. Because of this, films deposited on $\mathrm{SnO}_{2}$ nucleate faster, show complete coverage at earlier times, have smaller grain sizes, and seem to be thicker.

Pinholes were not observed in any CdS film deposited on $\mathrm{SnO}_{2}$. However, because peak-to-valley distances in these films are on the order of film thickness, pinholes may be camouflaged. This problem does not exist on the smoother films deposited on borosilicate and sodalime substrates. For these films, most samples did not show pinholes, and the few pinholes observed seemed to be due to incomplete coverage, other than a result of cluster deposition from homogeneous reaction. Because nucleation is much slower in these films, the observations are a good indication that films deposited on $\mathrm{SnO}_{2}$ indeed do not have pinholes. This result was expected and shows that the precautions we took to keep the homogeneous reaction to a minimum during film growth were effective.

Four CdS films with thicknesses over $100 \mathrm{~nm}$, two deposited by each process and using both types of $\mathrm{SnO}_{2}$, were heat-treated in 30-torr hydrogen atmosphere at $400^{\circ} \mathrm{C}$ for 15 minutes. Contrary to what we expected, the AFM images showed the same kind of grain structure as before treatment, including grain size. These results indicate that the changes in properties observed in these films after this kind of treatment are probably related to chemical and/or intragranular structural changes.

To complement the AFM analyses, we have done reflectance and transmission measurements. With these values, absorption coefficients $(\alpha)$ were calculated, and the bandgap values $\left(E_{g}\right)$ of the CdS films were determined. The bandgap values were obtained from the graph of $(\alpha E)^{2}$ vs. $E$, where $E$ is the energy of the

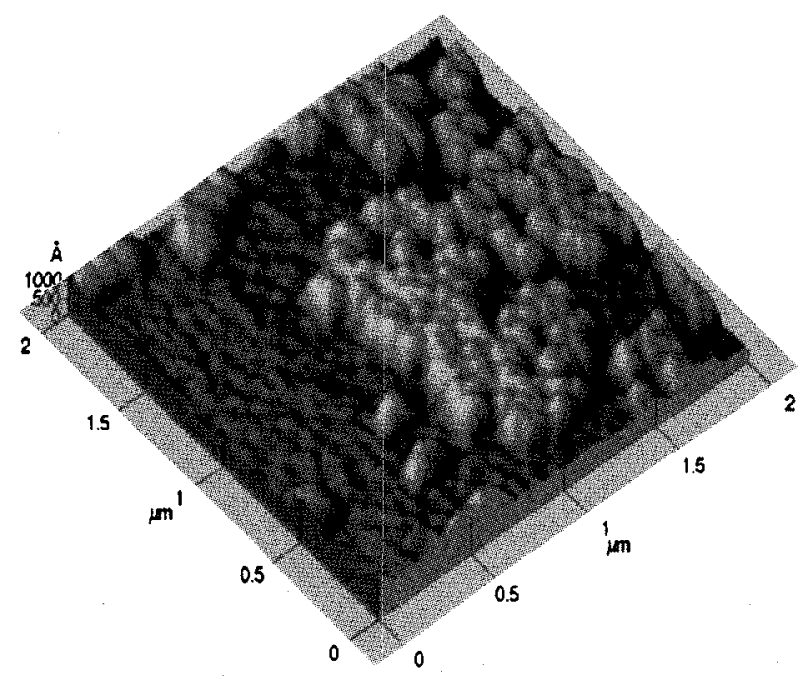

Fig. 3. CdS thin film deposited on borosilicate glass by process $B$, after 25 minutes deposition. 
analyzing radiation [9]. The value of $E_{g}$ was obtained by the intersection of the extrapolated linear part of the curve with the energy axis. To remove substrate effects from our analysis, the measurements were done on complete structures (film and substrate) and substrate structures without film.

The absorption coefficient of CdS in the region near to the bandgap, for all the films, was above $10^{4} \mathrm{~cm}^{-1}$, as observed previously by Danaher [5]. We found that the substrate structure is the most important factor affecting $E_{g}$, as shown in Fig. 4. The influence of the deposition process is not clearly evident. Films deposited on LOF $\mathrm{SnO}_{2} /$ sodalime presented bandgaps between $2.43 \mathrm{eV}$ and $2.44 \mathrm{eV}$, whereas films deposited on intrinsic $\mathrm{SnO}_{2}$ had bandgaps between $2.45 \mathrm{eV}$ and $2.48 \mathrm{eV}$. The reasons for this behavior are not well understood at the present time, but are possibly associated with different stress states in the films. It was also observed that films deposited on LOF $\mathrm{SnO}_{2}$ had larger values of absorption coefficient than films deposited on intrinsic $\mathrm{SnO}_{2}$, for all the range of wavelengths used in the analyses.

Transmittance and reflectance measurements were also done on hydrogen heat-treated samples. The results for all the samples was a reduction in bandgap value. The new values ranged from $2.33 \mathrm{eV}$ (previously $2.43 \mathrm{eV}$ ) to $2.42 \mathrm{eV}$ (previously $2.48 \mathrm{eV}$ ). One effect of $\mathrm{H}_{2}$ treatment in CdS is the preferential loss of $S$. The defects generated by this process can create shallow levels close to the conduction band, possibly being responsible for the observed decrease in bandgap. Another indication of the presence of such levels is that the absorption curves are not as smooth as before the treatment, pointing to the possible existence of more than one type of transition for charge carriers between bands. The main problem with the apparent reduction in bandgap is the increase in the optical loss in the CdS film. This can be observed even visually, with the darkening of the films. Finally, it was observed that films deposited by process B presented larger shifts in bandgap. This is probably associated with a different rate of $S$ release during $\mathrm{H}_{2}$ treatment compared to films deposited by process $A$.

\section{CONCLUSIONS}

- CaS thin films deposited by solution growth under normal device-processing conditions on $\mathrm{SnO}_{2}$ films present complete conformal coverage even for small thicknesses ( $40 \mathrm{~nm}$ or less). Final average grain size is established at early deposition times. No defects, such as pinholes, were observed in such films.

- Nucleation of CdS films on glass occurs by the formation of 3-dimensional islands, which grow and increase in number as deposition proceeds.

- The bandgap of CdS films deposited on $\mathrm{SnO}_{2}$ is influenced by the substrate structure.

- No effects of hydrogen heat treatment were found on the surface morphology of CdS films. However, effects of the treatment were observed in optical measurements by the reduction of bandgap values.

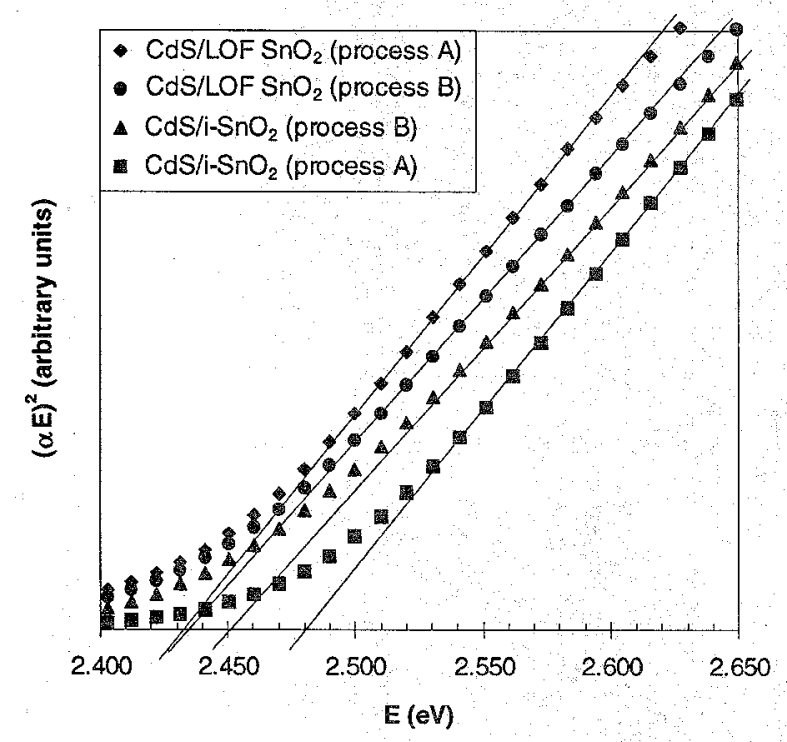

Fig. 4. $(\alpha E)^{2}$ curves showing bandgap values for $\mathrm{CdS}$ deposited with different parameters.

\section{ACKNOWLEDGMENTS}

The authors would like to thank Libbey-OwensFord and Solarex for providing the substrate samples used in this study. This work was performed, in part, under U.S. Department of Energy contract No. DE-AC36$83 \mathrm{CH} 10093$ with the National Renewable Energy Laboratory.

\section{REFERENCES}

[1] R.L. Call, N.K. Jaber, K. Seshan, and J.R. Whyte, Jr., Solar Energy Materials 2, 373 (1980).

[2] A. Mondal, T.K. Chaudhuri, and P. Pramanik, Solar Energy Materials 7, 431 (1983).

[3] W.E. Devaney, W.S. Chen, J.M. Stewart, and R.A. Mickelsen, IEEE Trans. Electron Dev. $37(2), 428$ (1990).

[4] T.L. Chu, S.S. Chu, N. Schultz, C. Wang, and C.Q. Wu, J. Electrochem. Soc. 139(9), 2443 (1992).

[5] W.J. Danaher, L.E. Lyons, and G.C. Morris, Solar Energy Materials 12, 137 (1985).

[6] Y.Y. Ma and R.H. Bube, J. Electrochem. Soc. 124(9), 1430 (1977).

[7] R. Sudharsanan and A. Rohatgi, Proc. $21^{\text {st }}$ IEEE Photov. Spec. Conf. (IEEE, New York, 1990) p. 504.

[8] J. Frommer and E. Meyer, J. Phys.: Condens. Matter 3, S1 (1991).

[9] E.J. Johnson, In: Semiconductors and Semimetals Vol. 3, R.K. Willardson and A.C. Beer eds. (Academic Press, New York, 1967) p. 168. 